MATEC Web of Conferences 11,01002 (2014)

DOI: $10.1051 /$ matecconf / 20141101002

(C) Owned by the authors, published by EDP Sciences, 2014

\title{
C-A-S-H gels formed in alkali-activated slag cement pastes. Structure and effect on cement properties and durability
}

\author{
F. Puertas ${ }^{1,2^{*}}$, M. Palacios ${ }^{1,3}$, H. Manzano ${ }^{5}$, J.S. Dolado ${ }^{4,2}$, A. Rico $^{6}$, J. Rodriguez $^{6}$ \\ ${ }^{1}$ Eduardo Torroja Institute for Construction Sciences (IETcc-CSIC), Madrid, Spain \\ ${ }^{2}$ Nanostructured and Eco-efficient Materials for Construction Unit, Associated Unit Labein- \\ Tecnalia/CSIC.IETcc, Spain \\ ${ }^{3}$ Institute for Building Materials-ETH Zurich, Switzerland \\ ${ }^{4}$ Labein-Tecnalia, Derio, Bilbao, Spain \\ ${ }^{5}$ Basque Country University UPV/EHU, Bilbao, Spain \\ ${ }^{6}$ Universidad Rey Juan Carlos, Móstoles, Madrid, Spain
}

\begin{abstract}
The development of alternatives to traditional Portland cement produced with more eco-efficient processes (lower energy consumption and $\mathrm{CO}_{2}$ gas emissions) is an item on climate change and innovation agendas. Alkaline cements and concretes are an effective alternative to traditional cements.

The structure of the C-S-H gel in Portland cements consists mostly of 14-nm tobermorite (with a chain length of five) and jennite (2-link chain). The mechanical properties of C-S-H gels can be explained in terms of the three types of packing found in these gels: low density (LD), high density (HD) and ultra-high density (UHD).

The main reaction product in alkali-activated slag (AAS) cements is a C-A-S-H gel, which adopts different structures depending on the nature of the alkaline activator. When the activator is a $\mathrm{NaOH}$ solution $\left(4 \% \mathrm{Na}_{2} \mathrm{O}\right.$ by slag weight), the C-A-S-H gel formed has an intermediate structure between 14-nm tobermorite with a chain length of five links and 11-nm tobermorite with 14 links. When the activator is a waterglass solution $\left(4 \% \mathrm{Na}_{2} \mathrm{O}\right.$ by slag weight), traits characteristic of 14-nm tobermorite with 11-link chains and 11-nm tobermorite with a chain length of 14 co-exist in the structure of the $\mathrm{C}-\mathrm{A}-\mathrm{S}-\mathrm{H}$ gel formed. This densely packed structure (with three HD states) yields excellent mechanical properties. Like the C-A-S-H gels obtained in $\mathrm{NaOH}(4 \% \mathrm{Na} 2 \mathrm{O})$-activated AAS paste, the C-A-S-H gels forming in AAS gels activated with waterglass have no UHD states.

The structure and composition of these C-A-S-H gels determine strength development in AAS mortars and concretes as well as their resistance to aggressive chemicals.
\end{abstract}

\section{Introduction}

Alkali-activated slags (AAS) cement development has been the object of much research in recent years because of the energy and environmental advantages of its production over ordinary Portland cement (OPC) manufacture. These cements are obtained by mixing vitreous granulated blast furnace slag with highly basic solutions such as waterglass $\left(\mathrm{Na}_{2} \mathrm{O} \cdot n \mathrm{SiO}_{2} \cdot m \mathrm{H}_{2} \mathrm{O}+\mathrm{NaOH}\right), \mathrm{NaOH}$ or $\mathrm{Na}_{2} \mathrm{CO}_{3}$, among others.

In terms of mechanical properties, AAS cements are comparable to OPC, particulary when waterglass is used as the activating solution $[1,2]$. At the same time, they exhibit greater durability when exposed to acid, sulphates or seawater than Portland cement systems [3, 5]. However, earlier studies [6-8] have shown that AAS cements and concretes carbonate more readily than OPCs and, in the presence of waterglass, they show a high autogenous and drying shrinkage rate. Nevertheless, when $\mathrm{NaOH}$ or
$\mathrm{Na}_{2} \mathrm{CO}_{3}$ solutions are used, cement shrinkage is comparable to the rate observed in OPC [9].

The properties exhibited by alkaline cements and concretes are directly related to the nature and structure of their main reaction product, $\mathrm{C}-\mathrm{A}-\mathrm{S}-\mathrm{H}$ gel. Further to the literature $[2,10,11]$, the C-A-S-H gel forming in the AAS pastes, like the C-S-H gel in OPC pastes [12], is made up with thetrahedrally coordinated silicate chains with a dreierketten structure though, the C-A-S-H gel chains in AAS cements are longer (up to 13 tetrahedra) than the C-S$\mathrm{H}$ gel chains in OPC systems (three or five tetrahedra) and, unlike the later, include aluminium in their structure, which replaces the silicon in bridging positions. On the grounds of MAS NMR and BSE/EDX findings, a number of researchers have concluded that the nature of the alkali activator used leads to differences in C-A-S-H gel structure and composition $[2,10,11]$.

Fernández-Jiménez et al. and Brough and Atkinson [10, 2] reported that the use of waterglass as an alkali activator induces the formation of a C-A-S-H gel with high $\mathrm{Si}^{2}$ and 
$\mathrm{Q}^{3}$ or $\mathrm{Q}^{\text {Poly }}$ contents and long, interwined chains. When the alkali activator is a $\mathrm{NaOH}$ solution, the C-A-S-H gel exhibit a high $\mathrm{Si} \mathrm{Q}^{2}$ unit content and long linear chains with no $\mathrm{Q}^{3}$ units which they did, however, detect when using $\mathrm{Na}_{2} \mathrm{CO}_{3}$ as the activating solution [10]. Finally, the nature of the activator also induces differences in the chemical composition [13]. To this respect, $\mathrm{Ca} / \mathrm{Si}$ in $\mathrm{C}-\mathrm{A}-\mathrm{S}-\mathrm{H}$ gel in AAS is substantially smaller than the C-S-H gel in OPC systems.

For the first time, the present study combines experimental and modern computational techniques to propose a new model for C-A-S-H gels found in waterglass- and $\mathrm{NaOH}$-activated AAS cements. A structural comparison between C-A-S-H and C-S-H gels is provided to facilitate the description. Also a relationship between gel structure and properties and durability is also presented.

\section{Materials, paste preparation and trials}

Table 1 gives the chemical composition of the blast furnace slag (BFS) and 42.5R I type Portland cement (OPC) used. The specific surface values for the BSF and OPC were 325 and $360 \mathrm{~m}^{2} / \mathrm{Kg}$. respectively. The vitreous phase content of the former was $99 \%$.

AAS and OPC pastes were prepared with liquid/solid ratios of 0.5 and 0.4 respectively. Two alkaline solutions were used for the alkali-activated slag pastes: waterglass and $\mathrm{NaOH}$, with a $\mathrm{Na}_{2} \mathrm{O}$ content of $4 \%$ of the slag weight. After 28-days storage in humidity chamber (98\% RH, $20 \pm$ $2{ }^{\circ} \mathrm{C}$ ), the AAS and OPC pastes were tested as described below.

${ }^{29} \mathrm{Si}$ and ${ }^{27} \mathrm{Al}$ MAS NMR: A BRUKER MSL 400 spectrometer was used. ${ }^{29} \mathrm{Si}$ and ${ }^{27} \mathrm{Al}$ spectra were obtained at resonance frequencies of 79.49 and $104.2 \mathrm{MHz}$. Chemical shifts values were found using tetramethylsilane and a $1 \mathrm{M} \mathrm{AlCl}{ }_{3} \cdot 6 \mathrm{H}_{2} \mathrm{O}$ solution as standards for ${ }^{29} \mathrm{Si}$ and ${ }^{27} \mathrm{Al}$, respectively.

Back-scattering scanning electron microscopy (BSE/EDX): A JOEL 5400 microscope fitted with an Oxford-Link ISIS EDX microanalysis unit was used. The samples were embedded in epoxy resin, cut, polished and carbon coated. Mechanical characterization with nanoindentation trials: These trials were conducted on 28-day paste samples prepared and cured as described above and subsequently cut and polished. Depth sensing indentation tests were conducted on a MTS System Co. XP nanoindenter fitted with a $100 \mathrm{~nm}$ nominal edge radius Berkovich tip. The load was applied with a $50-\mathrm{nN}$ calibrated electromagnetic coil and indentation loads of 300 and $500 \mu \mathrm{N}$ were used. The experimental set up described by Constantinides et al. was followed [14]. The Young's modulus and sample hardness were estimated for each indentation from the loaddisplacement curve using the procedure descrived by Oliver and Pharr for Berkovich tip.
Table 1. Chemical composition of BFS and OPC

\begin{tabular}{|c|c|c|}
\hline Wt. \% & BFS & OPC \\
\hline $\mathbf{C a O}$ & 41.37 & 64.41 \\
\hline $\mathbf{S i O}_{\mathbf{2}}$ & 34.95 & 17.91 \\
\hline $\mathbf{A l}_{\mathbf{2}} \mathbf{O}_{\mathbf{3}}$ & 13.11 & 5.17 \\
\hline $\mathrm{MgO}^{\mathbf{O}}$ & 7.12 & 1.30 \\
\hline $\mathbf{F e}_{\mathbf{2}} \mathbf{O}_{\mathbf{3}}$ & 0.69 & 3.85 \\
\hline $\mathbf{N a}_{\mathbf{2}} \mathbf{O}$ & 0.27 & 0.39 \\
\hline $\mathbf{K}_{\mathbf{2}} \mathbf{O}$ & 0.23 & 0.78 \\
\hline $\mathbf{S O}_{\mathbf{3}}$ & 0.04 & 2.64 \\
\hline $\mathbf{S}^{2-}$ & 1.92 & -- \\
\hline L.O.I & 2.02 & 0.78 \\
\hline I.R. & 0.11 & 0.29 \\
\hline
\end{tabular}

L.O.I: Lost on ignition. I.R.: Insoluble Residue

\section{Results}

\subsection{Mineralogical, microstructural and mechanical characterisation}

The ${ }^{29} \mathrm{Si}$ and ${ }^{27} \mathrm{Al}$ MAS NMR spectra for the AAS and OPC pastes are shown in Figs. 1 and 2, respectively, and Table 2 gives the deconvolution data for the ${ }^{29} \mathrm{Si}$ MAS NMR spectra.

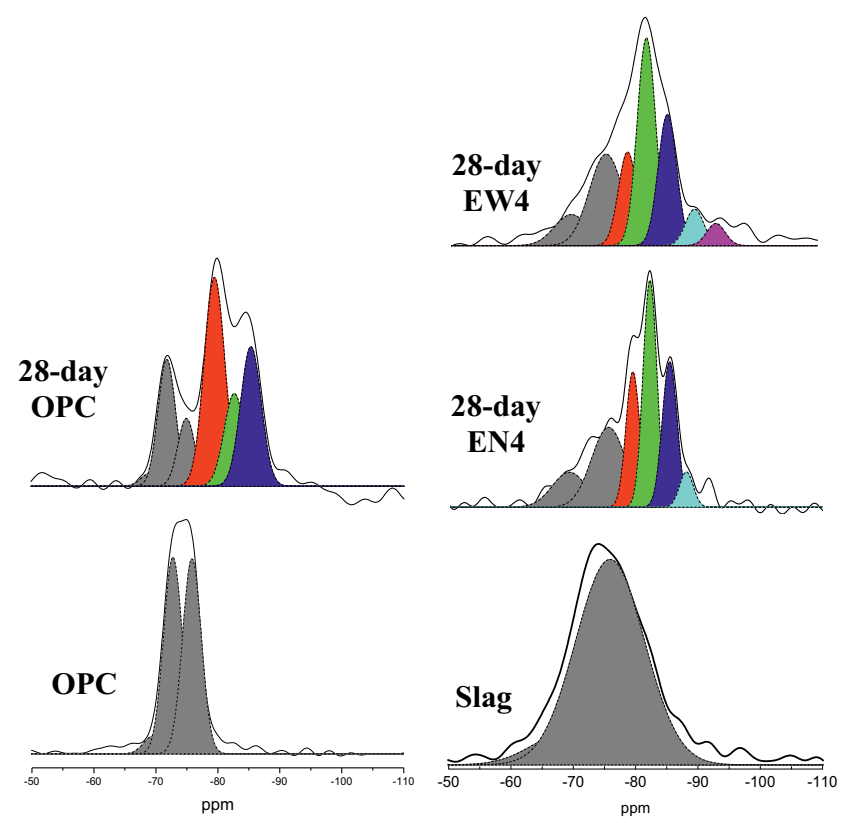

Fig. 1. ${ }^{29} \mathrm{Si}$ MAS NMR spectra for 28-day pastes: (EW4) waterglass-and (EN4) $\mathrm{NaOH}$-activated slag and OPC. 
The ${ }^{29} \mathrm{Si}$ spectrum for OPC paste contained three signals at $-68.0,-71.6$ and $-75.0 \mathrm{ppm}$ attributable to the isolated $\mathrm{Q}^{0}$ silicate tetrahedral in the clinker. The signals at $-79.0,-83.0$ and $-85.0 \mathrm{ppm}$, in turn, were respectively assigned to the $\mathrm{Q}^{1}, \mathrm{Q}^{2 \mathrm{~B}}$ and $\mathrm{Q}^{2} \mathrm{Si}$ units in the C-S-H gel. The ${ }^{29} \mathrm{Si}$ MAS NMR spectra for the 28-day waterglass- and $\mathrm{NaOH}-\mathrm{AAS}$ pastes had two signals at around -69.0 and $-75.0 \mathrm{ppm}$ attributed to unreacted $\mathrm{Q}^{0}$ and $\mathrm{Q}^{1}$ units in the anhydrous slag. A further five signals were detected on these spectra at $-78.0,-82.0,-85.0,-89.0$ and $-93.0 \mathrm{ppm}$ and respectively attributed to $\mathrm{Q}^{1}, \mathrm{Q}^{2}(1 \mathrm{Al})$ and $\mathrm{Q}^{2 \mathrm{~B}}, \mathrm{Q}^{3}(1 \mathrm{Al})$ and $\mathrm{Q}^{3}$ units $[10,15]$. Note that $Q^{3}$ units were identified in the waterglass- but not in the $\mathrm{NaOH}-\mathrm{AAS}$ pastes.

Table 2. ${ }^{29}$ Si MAS NMR signal deconvolution values for 28 day$\mathrm{OPC}$ and waterglass- and $\mathrm{NaOH}$-activated slag pastes.

\begin{tabular}{|c|c|c|c|c|}
\hline & & $\begin{array}{c}28 \text { day } \\
\text { OPC }\end{array}$ & $\begin{array}{c}28 \text { day } \\
\text { EW4 }\end{array}$ & $\begin{array}{c}28 \text { day } \\
\text { EN4 }\end{array}$ \\
\hline \multirow{9}{*}{$\begin{array}{c}\mathbf{Q}^{0} / \mathbf{Q 1}^{-} \\
\text {Anhydrous }\end{array}$} & $-\delta(\mathrm{ppm})$ & 68.0 & 69.7 & 69.2 \\
\hline & Width & 3.7 & 7.4 & 7.0 \\
\hline & $\%$ Integral & 2.3 & 7.6 & 9.1 \\
\hline & $-\delta(\mathrm{ppm})$ & 71.6 & -- & -- \\
\hline & Width & 3.7 & -- & -- \\
\hline & $\%$ Integral & 20. & -- & -- \\
\hline & $-\delta(\mathrm{ppm})$ & 75.0 & 75.4 & 75.4 \\
\hline & Width & 3.7 & 7.4 & 7.0 \\
\hline & $\%$ Integral & 10.3 & 26.6 & 25.0 \\
\hline \multirow{3}{*}{$\begin{array}{c}Q^{1} \\
\text { End of chain }\end{array}$} & $-\delta(\mathrm{ppm})$ & 79.5 & 78.9 & 79.5 \\
\hline & Width & 4.0 & 3.5 & 2.7 \\
\hline & $\%$ Integral & 35.5 & 12.6 & 16.1 \\
\hline \multirow{3}{*}{$\begin{array}{c}Q^{2}(1 \mathrm{Al}) \\
\& Q^{2 B}\end{array}$} & $-\delta(\mathrm{ppm})$ & 83.0 & 82.0 & 82.3 \\
\hline & Width & 4.0 & 3.5 & 2.7 \\
\hline & $\%$ Integral & 12.3 & 28.7 & 28.3 \\
\hline \multirow{3}{*}{$\mathbf{Q}^{2}$} & $-\delta(\mathrm{ppm})$ & 85.3 & 85.4 & 85.5 \\
\hline & Width & 4.0 & 3.5 & 2.7 \\
\hline & $\%$ Integral & 19.6 & 17.9 & 17.6 \\
\hline \multirow{3}{*}{$Q^{3}(1 \mathrm{Al})$} & $-\delta(\mathrm{ppm})$ & -- & 89.9 & 88.1 \\
\hline & Width & -- & 3.5 & 2.7 \\
\hline & $\%$ Integral & -- & 4.3 & 3.9 \\
\hline \multirow{3}{*}{$\mathbf{Q}^{3}$} & $-\delta(\mathrm{ppm})$ & -- & 93.4 & -- \\
\hline & Width & -- & 3.5 & -- \\
\hline & $\%$ Integral & -- & 2.3 & -- \\
\hline
\end{tabular}

The signals on the ${ }^{27} \mathrm{Al}$ MAS NMR spectrum for the OPC pastes appeared at: $70.0 \mathrm{ppm}$, attributable to the tetrahedral $\mathrm{Al}$ present in the anhydrous phases of calcium aluminate, calcium ferroaluminate and alite in the cement clinker, $13.6 \mathrm{ppm}$, assigned to the octahedral $\mathrm{Al}$ in ettringite, $9.0 \mathrm{ppm}$, attributed to monosulfoaluminate and the unhydrated ferritic phase, $3.0 \mathrm{ppm}$, associated with the octahedral $\mathrm{Al}$ in the hydrated aluminate phases [15]. The ${ }^{27} \mathrm{Al}$ MAS NMR for the $\mathrm{NaOH}-$ and waterglass-AAS paste had four signals: $\sim 70.0$ and $\sim 60.0 \mathrm{ppm}$, associated with tetrahedral Al units and $\sim 40.0$ and $\sim 9.0 \mathrm{ppm}$, associated with pentahedral and octahedral $\mathrm{Al}$ units, respectively [10, 15, 16]. The band at around $107 \mathrm{ppm}$ observed in the spectra was associated with a rotational band on the central
${ }^{27} \mathrm{Al}$ signal due to the presence of ferromagnetic $\mathrm{Fe}_{3} \mathrm{O}_{4}$ or antiferromagnetic $\mathrm{Fe}_{2} \mathrm{O}_{3}[17,18]$.

The SEM/BSE micrographs for the three pastes in Fig. 3 show the difference in their appearance. The white particles are anhydrous cement or vitreous slag grains. The greyish matrix is essentially the C-S-H or C-A-S-H gel. This matrix was observed to be more compact and less porous in the waterglass-AAS than in the other two materials. The dense microcracking was a result of the intense drying shrinkage in these materials [19]. The $\mathrm{Ca} / \mathrm{Si}$ ratio of the gels formed was determined by EDS analysis in this area (at least, 30 analysis per sample) and it was found that the $\mathrm{Ca} / \mathrm{Si}$ ratio for the 28-day OPC paste was around $2.19 \pm 0.22$ whereas it showed a lower value for the $\mathrm{NaOH}$ and waterglass- AAS pastes $(1.10 \pm 0.11$ and $0.96 \pm 0.10$, respectively).
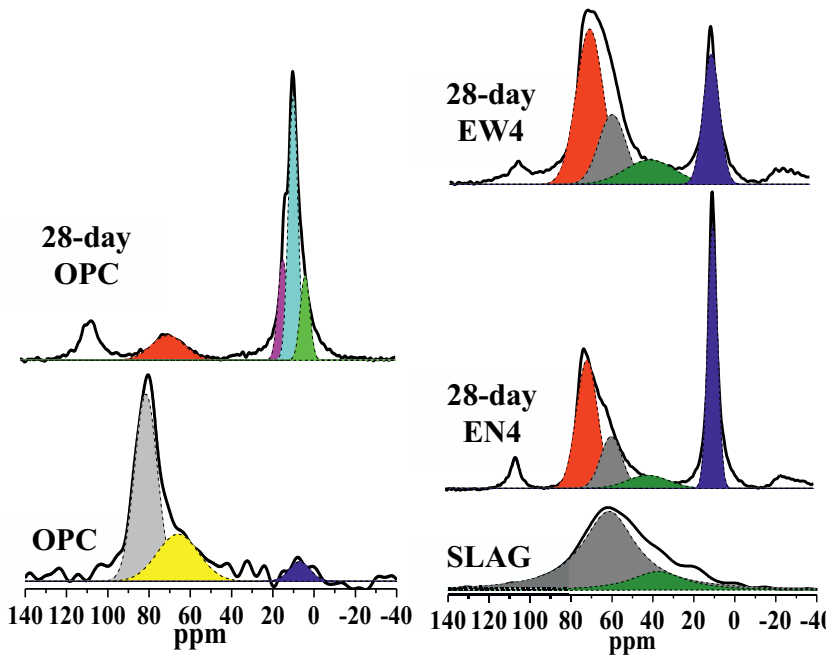

Fig. 2. ${ }^{27} \mathrm{Al}$ MAS NMR spectra for 28-day pastes: (EW4) waterglass-and (EN4) $\mathrm{NaOH}$-activated slag and OPC.
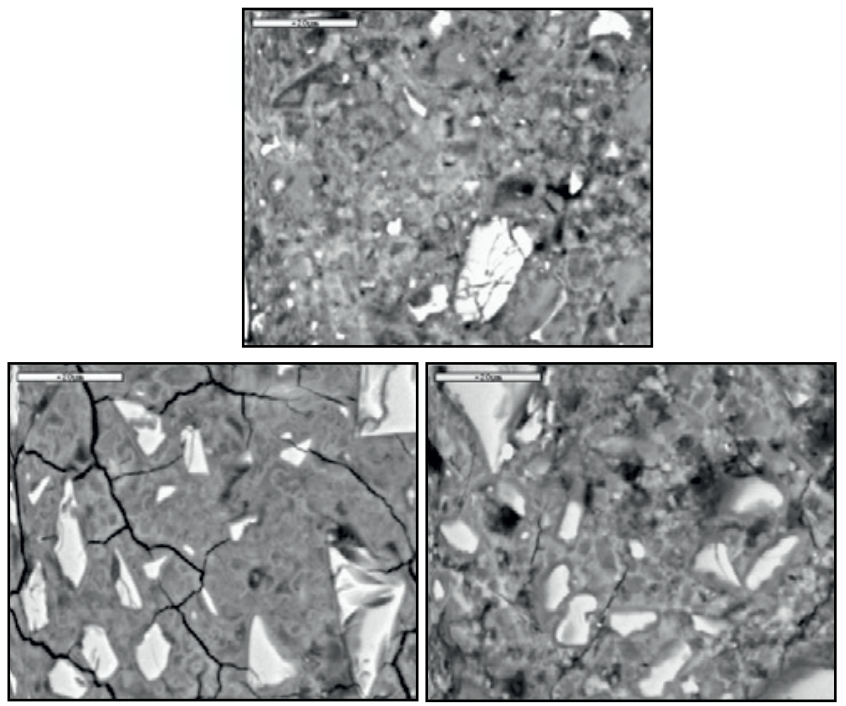

Fig. 3 BSEM images of (a) OPC and (b) waterglass- and (b) $\mathrm{NaOH}$-activated pastes 
Fig. 4 represents the contour maps of Young's modulus plotted by interpolating the results of the nanoindentation findings to locate representative microstructural areas (see also Table 3). A distinct correlation was found between the microstructure visible in the BSE/SEM images (Fig. 4 a, c and e) and the mechanical contour maps (Fig. 4 b, d and f). In other words, mechanical behaviour varied with the microstructural characteristics of the samples.

Table 3. Hardeness and Young's modulus results from nanoindentation trials.

\begin{tabular}{|c|c|c|c|c|c|}
\cline { 3 - 6 } \multicolumn{2}{|c}{} & $\begin{array}{c}\text { Young's } \\
\text { modulus } \\
\text { range } \\
\text { (GPa) }\end{array}$ & $\begin{array}{c}\text { Maximum } \\
\text { peak } \\
\text { value } \\
\text { (GPa) }\end{array}$ & $\begin{array}{c}\text { Hardness } \\
\text { range (GPa) }\end{array}$ & $\begin{array}{c}\text { Maximu } \\
\text { m peak } \\
\text { value } \\
\text { (GPa) }\end{array}$ \\
\hline \hline \multirow{3}{*}{$\begin{array}{c}\text { OPC } \\
\text { 28d }\end{array}$} & A & $16-24$ & 19 & $0.40-0.50$ & 0.45 \\
\cline { 2 - 6 } & B & $25-33$ & 28 & $0.80-1.00$ & 0.85 \\
\hline \multirow{2}{*}{$\begin{array}{c}\text { EN } \\
\text { 28d }\end{array}$} & A & $34-44$ & 39 & $1.20-1.40$ & 1.25 \\
\cline { 2 - 6 } & B & $20-26$ & 23 & $0.66-0.84$ & 0.73 \\
\cline { 2 - 6 } & C & $35-43$ & 38 & $1.14-1.32$ & 1.24 \\
\hline \multirow{3}{*}{$\begin{array}{l}\text { EW } \\
\text { 28d }\end{array}$} & A & $28-34$ & 32 & $0.84-1.00$ & 0.94 \\
\cline { 2 - 6 } & B & $34-40$ & 37 & $1.08-1.26$ & 1.18 \\
\cline { 2 - 6 } & C & $41-47$ & 44 & $1.35-1.53$ & 1.43 \\
\hline
\end{tabular}
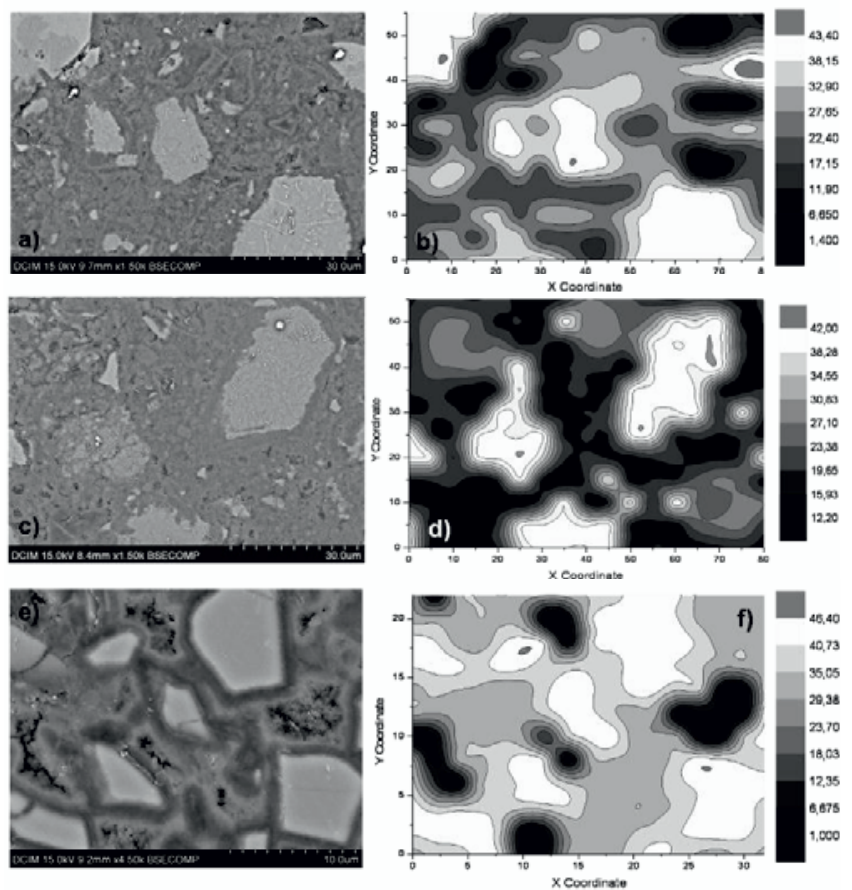

Fig. 4. a) SEM images showing: a) a representative portion of the OPC sample; b) Young's modulus contour map for a); c) SEM image showing a representative portion of the EN sample; $d$ )

Young's modulus contour map for c); e) SEM image showing a representative portion of the EW sample; f) Young's modulus contour map for e).
Based on nanoindentation trials results, a number of conclusions can be drawn. Both mechanical properties exhibited more than one distribution pattern in all the samples (distributions $\mathrm{A}, \mathrm{B}$ y $\mathrm{C}$ in Table 3), an indication that mechanical behaviour differs in different regions of cement materials. According to the results gathered in Table 3, three general patterns were present. The existence of three mechanical states in OPC concurs with the general belief that C-S-H may exhibit low (LD), high (HD) [20] or ultra-high (UHD) density states [21]. The present study shows for the first time that clearly differentiated mechanical states also exist in AAS C-A-S-H gels, which suggest that the density regimens are intrinsic from the dissolution-precipitation process.

\section{Discussion: a model for C-A-S-H nanostructure}

Further to the mineralogical and structural characterisation conducted on OPC and AAS pastes, the C-S-H and C-A-S$\mathrm{H}$ gels forming in these pastes, cured under the same conditions and for the same length of time, exhibited substantial mineralogical and structural differences, findings which concurred with prior reports $[10,16]$.

The C-S-H gel forming in OPC pastes had a chain-like structure and was characterised by a low $\mathrm{Al}$ content, low $\Sigma \mathrm{Q}^{2} / \mathrm{Q}^{1}$ ratios and a mean chain length (MCL) of three to five tetrahedra (see Table 4). Differences in gel structure were observed in the AAS pastes depending on the nature of the alkali activator. When it was a $\mathrm{NaOH}$ solution, the $\mathrm{C}$ A-S-H gel contained $\mathrm{Al}$ in its composition (in chain bridging positions) and exhibited a high $\mathrm{Q}^{2}(1 \mathrm{Al})$ content, low $\mathrm{Q}^{3}$ unit percentages, an MCL of eight and high $\Sigma \mathrm{Q}^{2} / \mathrm{Q}^{1}$ ratios. When a waterglass solution was used as the activator, the C-A-S-H gel formed had high percentages of $\mathrm{Al}$, high $\Sigma \mathrm{Q}^{2} / \mathrm{Q}^{1}$ ratios, a higher $\mathrm{Q}^{3}$ unit content and a mean chain length of around 11 tetrahedra. The presence of $\mathrm{Q}^{3}$ units in the AAS gels was an indication of intertwining between the gel chains, with the formation of laminar structures in some areas.

Tabla 4 Data obtained form ${ }^{29}$ Si MAS NMR signal deonvolution values

\begin{tabular}{c|c|c|c}
\hline & 28-Day OPC & 28-Day EW & 28-Day EN \\
\hline \hline $\mathbf{M C L}$ & 3.80 & 12.71 & 8.00 \\
\hline $\boldsymbol{\Sigma} \mathbf{Q}^{2} / \mathbf{Q}^{\text {total }}$ & 0.47 & 0.71 & 0.70 \\
\hline $\mathbf{Q}^{\mathbf{2}} \mathbf{( 0 A I )} / \mathbf{Q}^{\mathbf{2}} \mathbf{( 1 \mathbf { A l } )}$ & -- & 0.62 & 0.62 \\
\hline $\boldsymbol{\Sigma} \mathbf{Q}^{\mathbf{2}} / \mathbf{Q}^{\mathbf{1}}$ & 0.90 & 3.70 & 2.84 \\
\hline $\mathbf{A l} / \mathbf{S i}$ & -- & 0.24 & 0.23 \\
\hline
\end{tabular}

The BSEM/EDS findings confirmed the NMR results, for longer, intertwined chains of silicate tetrahedra, lower the $\mathrm{Ca} / \mathrm{Si}$ ratio in these gels. While the $\mathrm{Ca} / \mathrm{Si}$ ratio in the OPC paste $\mathrm{C}-\mathrm{S}-\mathrm{H}$ gel was $2.19 \pm 0.22$, the value of this parameter declined to $1.10 \pm 0.11$ in the C-A-S-H gel found 
in $\mathrm{NaOH}-\mathrm{AAS}$ (EN-AAS) and to $0.96 \pm 0.10$ in the waterglass-AAS (Wg-AAS) material. In other words, increasing the $\mathrm{Al}$ content in the gel raised the mean chain length, favoured linear chain intertwining and lowered the $\mathrm{Ca} / \mathrm{Si}$.

The C-S-H gel forming in OPC pastes may be described as an imperfect tobermorite $1.4 \mathrm{~nm}$. The difference in the $\mathrm{Ca} / \mathrm{Si}$ ratio, which is lower in defective tobermorite $1.4 \mathrm{~nm}$ than in C-S-H gel, may be attributed to the co-existence of jennite-like structures in the latter, whose $\mathrm{Ca} / \mathrm{Si}$ ratios have been suggested to be much higher (up to 2.2) in prior empirical and theoretical studies (see numerical models values for structural parameters in ref. 22). The C-S-H samples analysed here, with an experimental MCL value of 3.8 , may be regarded to comprise $60 \% \mathrm{~T} 14$ (5) and $40 \% \mathrm{~J}$ (2).

The $\mathrm{Ca} / \mathrm{Si}$ ratio and the percentage of $\mathrm{Q}^{3}$ sites in the $\mathrm{C}$ A-S-H gel formed in $\mathrm{NaOH}-\mathrm{AAS}$ suggest that its atomic scale structure might be close to the tobermorite $1.1-\mathrm{nm}$ model. Given the experimental mean chain length, $\mathrm{Ca} / \mathrm{Si}$, $\mathrm{Al} / \mathrm{Si}$ and $\mathrm{Q}^{3} / \mathrm{Q}^{2}$ ratios, these $\mathrm{C}-\mathrm{A}-\mathrm{S}-\mathrm{H}$ varieties might well be described to contain a mix of tobermorite 1.4-nm with 5 link chains and tobermorite 1.1-nm with 14 link chains components. When the activator is waterglass, an educated suggestion would be that these varieties of C-A-S-H are a mix of tobermorite 1.4-nm with 11 link chains and tobermorite 1.1 with 14 link chain configurations (see numerical models values for structural parameters in ref. 22).

From the standpoint of mechanical performance, the nanoindentation studies showed that, as in C-S-H gel, C-A$\mathrm{S}-\mathrm{H}$ gel had distinct mechanical states. Nonetheless, the structural and compositional differences in C-S-H and C-A$\mathrm{S}-\mathrm{H}$ gels translated into differences in their moduli of elasticity and hardness. The data in Figure 4 and Table 3 show that the highest strength values were obtained for Waterglass-AAS gels, followed by the OPC gels and finally, the $\mathrm{NaOH}-\mathrm{AAS}$ gels. This lower strength in the $\mathrm{NaOH}-\mathrm{AAS}$ pastes may be explained by the much higher porosity found in these pastes than in the Waterglass-AAS materials, as confirmed by the BSEM.

The existence of three mechanical states is consistent with prior studies [21] that relate these states in $\mathrm{C}-\mathrm{S}-\mathrm{H}$ gel to packing density: LD, HD and UHD. Attending to prior studies, the UHD state in C-S-H gel arises from an intimate nanocomposite where nanoscale Portlandite reinforces C-S$\mathrm{H}$ by partially filling the $\mathrm{C}-\mathrm{S}-\mathrm{H}$ gel pores [23]. The existence of the three regimens for different systems indicates that the packing density is an intrinsic characteristic of the hydration reactions. Different packing densities arise from the available space, with looser packing far from the clinker or fly ash particles, and tighter packing close to them.

In a previous study, the authors of the present investigation performed atomistic simulations with the force field method [22]. Based on these results and applying a self consistent (SC) micromechanical method, the effect of porosity on elastic properties was determined. This study yielded packing factors for the C-S-H states of around $0.68,0.77$ and 0.9 [22], which concur extremely well with the estimates provided previously [20, 21], namely $0.69 \pm 0.05,0.78 \pm 0.02$ and $0.89 \pm 0.03$. LD varieties are normally regarded to be random C-S-H particles, since the random limit packing factor of spherical particles is 0.64 [24]. The packing factors for the HD varieties are similar to the packing factors for ordered face-centred cubic (fcc) or hexagonal close packed (hcp) spheres (0.74).

The extremely high packing factor corresponding to the UHD states cannot be explained in terms of single spherical particles. Vandamme et al. [21] maintained that this factor would be due to random packing of two spherical particle classes $\left(1-(1-0.64)^{2}\right)$.

Three mechanical regions can be attributed to $\mathrm{NaOH}$ AAS C-A-S-H particles with packing factors of around $0.63,0.68$ and 0.79 [22]. The first two states fall within category LD (similar to the random packing limit), whereas the third indisputably lies within what may be regarded to be an HD state. Unlike OPCs, EN C-A-S-H gels cannot exist in the UHD state because $\mathrm{NaOH}-\mathrm{AAS}$ have no portlandite, which is essential to the existence of that state [25].

Waterglass-AAS C-A-S-H gels exhibit better intrinsic properties than the other two materials as a result of their high relative tobermorite-1.1 population. The SC micromechanical model findings corroborate the nanoindentation results: these gels form a very dense structure where waterglass-AAS C-A-S-H gels exhibit three mechanical states, with packing factors of $0.71,0.73$ and 0.79 . Given the proximity of these values to the factor for the HD category, they were classified accordingly. The EW C-A-S-H gels, like their EN counterparts, have no UHD states as a result of the absence of portlandite.

The different nanostructure of C-S-H and C-A-S-H gels explain the diverse behaviour of these materials from drying shrinkage [26] and carbonation trials [27,28]. High drying shrinkage and carbonation rates in Waterglass-AAS C-A-S-H pastes.

\section{Conclusions}

1.- The C-S-H and C-A-S-H gels forming in OPC and AAS pastes exhibit compositional and structural differences. The former is characterised by a chain-like structure, a low Al content and low $\Sigma \mathrm{Q}^{2} / \mathrm{Q}^{1}$ ratios and a mean chain length of three to five tetrahedra. In the AAS pastes, the C-A-S-H gels formed exhibit structural differences depending on the nature of the alkali activator. When it is an $\mathrm{NaOH}$ solution, the C-A-S-H gel contains $\mathrm{Al}$ in its composition (in bridge positions) and has a high $\mathrm{Q}^{2}(1 \mathrm{Al})$ content, low $\mathrm{Q}^{3}$ unit percentages, an MCL of nine and high $\Sigma \mathrm{Q}^{2} / \mathrm{Q}^{1}$ ratios. When a waterglass solution is used as the activator, the C-A-S-H gel formed has high percentages of $\mathrm{Al}$ in tetrahedral 
positions, high $\Sigma \mathrm{Q}^{2} / \mathrm{Q}^{1}$ ratios, a higher $\mathrm{Q}^{3}$ unit content and a mean chain length of around 11 tetrahedra. The presence of $\mathrm{Q}^{3}$ units in the AAS gels is an indication of the gel chain intertwining, with the formation of laminar structures in some areas.

2.- Modulus of elasticity and hardness values were determined for the gels formed in the OPC pastes, and for the first time for the gels present in AAS pastes, with nanoindentation trials. The values vary depending on the compositional and structural characteristics of the gels. The present experimental study showed for the first time that like the C-S-H gel in OPCs, the C-A-S-H in AAS can be found in different mechanical states. This suggests that the presence of difference packing efficiencies is intrinsic from the hydration reactions.

3.- The tobermorite structures on which the C-A-S-H gels in AAS pastes can be patterned were established for the first time, and compared to the gel in an OPC paste, using experimentally validated modelling techniques.

3.1.- The C-S-H gel in a 28-day OPC paste corresponds primarily to tobermorite $14 \mathrm{~nm}$ (mean chain length of five tetrahedra) and jennite (two tetrahedra). The mechanical properties of C-S-H gels can be explained on the grounds of three types of packing, i.e., LD, HD and UHD.

3.2.- The structure of a C-A-S-H gel obtained in 28-day $\mathrm{NaOH}-\mathrm{AAS}$ pastes can be regarded to fall in between tobermorite $1.4 \mathrm{~nm}$ with a mean chain length of five and tobermorite $1.1 \mathrm{~nm}$ with a mean length of 14 tetrahedra. The high porosity induced by the molecular disorder explains the scant elasticity of the gel forming under these conditions, which comprises primarily LD-type states. Although a small population of HD states is present in the gel, the absence of portlandite prevents the formation of UHD states.

3.3.- In C-A-S-H gels forming in 28-day waterglass-AAS, the structure found for the C-A-S-H gel formed is indicative of the co-existence of tobermorite $1.4 \mathrm{~nm}$, with a chain length of 11 , and tobermorite $1.1 \mathrm{~nm}$, with a chain length of 14 tetrahedra. This very densely packed structure (three HD states) gives rise to excellent mechanical properties. Like the C-A-S-H gels obtained in $\mathrm{NaOH}-\mathrm{AAS}$ paste, the C-A$\mathrm{S}-\mathrm{H}$ gels forming in Waterglass-AAS gels have no UHD states.

\section{References}

1. A. Fernández-Jiménez, F. Puertas, J.G. Palomo, Cem.Concr. Res. 29, (1999)

2. A.R. Brough, A. Atkinson, Cem. Concr. Res. 32, (2002)

3. T. Bakharev, J.G. Sanjayan, Y.B. Cheng, Cem. Concr. Res. 32, (2002)

4. T. Bakharev, J.G. Sanjayan, Y.B. Cheng, Cem. Concr. Res. 33, (2003)
5. F. Puertas, R. Mejía de Gutierrez , A. FernándezJiménez, S. Delvasto, J. Maldonado, Mater. Construcc. 52, 267 (2002)

6. F. Puertas, M. Palacios, T. Vázquez, J. Mater. Sci 41 (2006)

7. T. Bakharev, J.G. Sanjayan, Y.B Cheng, Cem. Concr. Res. 31 (2001)

8. M. Palacios, F. Puertas, J. Amer. Ceram. Soc. 89, 10 (2006)

9. M. Palacios, F. Puertas, Cem. Concr. Res. 37 (2007)

10. A. Fernández-Jiménez, F. Puertas, I. Sobrados, J. Sanz, J. Am. Ceramic Soc. 86, 3 (2003)

11. A.R. Brough, A. Atkinson, Cem. Concr. Res. 32 (2002)

12. I.G. Richardson, Cem. Concr. Res. 38 (2008)

13. I. Lecomte, C. Henrist, M.Li'egeois, F. Maseri, A. Rulmont, R. Cloots, J. Eur. Ceram. Soc. 26 (2006)

14. Constantinides G, Ulm FJ. Journal of Mechanic and Physic Solids 55 (2007)

15. R.J. Kirkpatrick, Y.X. Cong, An in introduction to ${ }^{27} \mathrm{Al}$ and ${ }^{29} \mathrm{Si}$ NMR spectroscopy of cements and concretes. Application of NMR spectroscopy to cement science (Ed. P. Colomet and A. Grimmer 1994)

16. J. Skibsted, H.J. Jakobsen, C. Hallt, Adv. Cem. Bas. Mat. 7(1998)

17. F. Brunet, T. Charpentier, C.N. Chao, H. Peycelon, A. Nonat, Cem. Concr. Res. 40 (2010)

18. E. Oldfied, R.A. Kinsey, K.A. Smith, J.A. Nichols, R.J. Kirkpatrick, J. Magn. Reson 51 (1983)

19. M. Palacios M. PhD. Autonoma University of Madrid (2006)

20. G. Constantinidis, F.J. Ulm, Mech. Phys. Sol. 55 (2007)

21. M. Vandamme, F.J. Ulm, Proc. Natl. Acad. Sci. USA (2009)

22. F. Puertas, M. Palacios, H, Manzano, J.S. Dolado, A. Rico, J. Rodríguez. J. Eur. Ceram. Soc. 31, 12 (2011)

23. N.H. de Leeun, G.W. Watson, S.C. Parker, J. Phys. Chem. 99, 47 (1995)

24. C. Song, P. Wang, H.A. Makse. Nature 45, 3 (2008)

25. J. Chen, L. Sorelli, M. Vandamme, J.F. Ulm, J. Am. Ceram. Soc 93, 5 (2010)

26. M. Palacios, F. Puertas. Cem Concr Res. 37, 691-702 (2007)

27. F. Puertas, M. Palacios, T. Vázquez. J. Mater. 41 (10) 3071-3082 (2006)

28. M. Palacios, F. Puertas. J. Am. Ceram. Soc. 89 (10), 3211-3221 (2006)

\section{Acknowledgemets}

This research was funded by the European Union under contract NMP3-SL-2008-214030 and the Spanish Ministry of Science and Innovation under project BIA2010-15516. Thanks also to Dr. Cristina Ruiz Santa Quiteria from your contribution in the preparation of this communication. 